\section{Apologia da Polêmica}

Apologia da Polêmica, de Ruth Amossy, teve publicada a primeira edição em 2017, pela Editora Contexto: São Paulo. Na obra, a professora emérita na Universidade de Tel Aviv, diretora de um grupo de pesquisa em Análise do Discurso, Argumentação e Retórica, ligado a mesma universidade, além de editora da revista Argumentacion et analyse du discours, investiga com profundidade a natureza dos debates conflituosos nos quais se sustenta a democracia numa sociedade plural. Com base em exemplos reais - de um debate televisivo a um fórum de discussão na internet -, a autora analisa metodicamente e responde a questões que a polêmica pública suscita, interrogando sobre seu funcionamento e suas funções no espaço democrático. Ela mostra como a polêmica é um elemento fundamental para a constituição da democracia e do próprio espaço público.

A obra apresenta o título Apologia-semanticamente entendido como modo de defesa, suporte ou apoio em prol de algo ou alguém, desenvolvido em forma de discurso oral ou escrito como uma defesa entusiasmada, de elogio ou exaltação à Polêmica - como a prática de provocar disputas e causar controvérsias em inúmeros campos discursivos (político, religioso, artístico, filosófico, literário etc.); trata-se de um recurso argumentativo necessário que defende ou justifica as tomadas de decisão nas mais diferentes esferas da vida humana para o avanço do conhecimento nos respectivos campos de atuação.

Neste estudo, a especialista em Análise do Discurso parte da visão de "má reputação" (2017, p. 7) em que a polêmica tem de atrair críticas dos censores de todos os lados, desde o uso da Retórica antiga, até os debates que nutrem a democracia contemporânea, para questionar a incapacidade que os cidadãos, pessoas políticas, têm para seguir as regras do debate racional, movidos pela paixão ou pela curiosidade que as mídias provocam no espetáculo da violência verbal e degradação dos costumes e a influência nefasta das novas mídias. Na atualidade, os conflitos de opinião e seus escândalos ocupam um lugar preponderante na cena política, assim como nas mídias. Se a polêmica é tão depreciada, por que ela invade, de forma tão persistente, o espaço público? Por que ocupa uma posição privilegiada nas mídias? Esses e outros aspectos dão ensejo à composição da pesquisa que Ruth Amossy realiza como estudiosa sobre a temática.

A obra Apologia da Polêmica estrutura-se em cinco partes: introdução, três capítulos de desenvolvimento e a conclusão. A introdução traz uma reflexão geral sobre o funcionamento, as funções sociais no espaço democrático, em que divergências de opinião podem se manifestar livremente com a participação de todos. Para compreender o papel que a polêmica pode desempenhar, é preciso ver, in loco, os casos
Prof. ${ }^{a}$ Ma. Elizabeth Maria Ziliotto

Mestrado em Letras pela Universidade Presbiteriana Mackenzie - UPM. Docente do Ensino Superior, na modalidade EAD do Curso de Letras Português-Inglês/ Espanhol da Universidade Cruzeiro do Sul - UCS e Universidade da Cidade de São Paulo - UNICID.

E-mail: emzilliotto@ yahoo.com.br 
concretos e acompanhar como ela se constrói discursivamente e modela a comunicação.

Na primeira parte do desenvolvimento, estão as reflexões teóricas que tratam de como "gerir o desacordo em democracia: por uma retórica do dissenso", conceito entendido como a falta de concordância a respeito de algo, seguida pelas "questões de definição do que é a polêmica". Nessa parte inicial, importa saber sobre o fenômeno global que a polêmica suscita, explorar o fenômeno sociodiscursivo em sua expressão e complexidade e trazer algumas referências teóricas. Perelman e Olbrechts-Tyteca, em O tratado da argumentação: a nova retórica, definem a argumentação como "o estudo das técnicas discursivas que permitem provocar ou aumentar a adesão dos espíritos às teses que se apresentam à sua aprovação (1970, p. 5). Essa nova retórica não se interessa pelo raciocínio autônomo na mente de um sujeito pensante, mas pelo raciocínio verbal em situação de comunicação que visa ao acordo. Parte do princípio de que o discurso, estudado como interação entre dois ou mais participantes, permite aos sujeitos em comunicação construírem respostas comuns aos problemas que se apresentam em dado espaço social. Em outras palavras, Perelman entende que é preciso argumentar para chegar a uma solução comum que pareça aceitável e plausível à maioria. Isso significa que o dissenso deve ser superado a todo custo, reinfundindo a racionalidade no seio dos comportamentos humanos, o acordo sobre o aceitável e o plausível permite conter surtos de irracionalidade e de violência.

Para fundamentar a linha de pensamento que defende a gestão do raciocínio compartilhado para a resolução dos conflitos, convém lembrar Habermas, cuja concepção de comunicação social mantém a relação de troca verbal, da razão e do acordo que se encontra no coração da retórica. Para o estudioso, a noção de espaço ou esfera pública repousa sobre um modelo de discussão racional em que os cidadãos chegam a um acordo, através de livre interação verbal, designada por um domínio da vida social em que se forma a opinião pública, também aberta a todos os cidadãos, jornais e revistas, rádio e televisão, bem como todas as mídias que desempenham um papel constitutivo. O espaço público compõe uma instância crítica que assegura a mediação pelo agir comunicacional entre sociedade e o Estado para garantir o bom funcionamento da democracia. Para Chantal Mouffe (2000), a revalorização do dissenso como ciência política, cuja teoria da democracia deliberativa apresenta o "pluralismo agonístico", reconhece e legitima o conflito e o dissenso no coração do processo democrático como seu próprio motor e recusa reprimir a imposição de ordem autoritária.

Além do breve apontamento sobre essas referências teóricas e outras mais, na primeira parte, convém destacar, na sequência, algumas definições apresentadas na obra sobre o que é a polêmica, inicialmente citado por Kerbrat-Orecchioni, 'debate vivo ou agressivo' (1980, p. 3). Vem do grego polemikos, relativo à "guerra de caneta", com sentido metafórico de vocabulário militar. As definições lexicográficas relacionadas à etimologia deram origem à forma substantiva, adjetiva e verbal (polemizar). O trabalho de Amossy, com a argumentação retórica, ligada à deliberação, acabou por fazê-la questionar sobre a polêmica. De fato, a retórica estuda o processo pelo qual os homens discutem um assunto sobre o que eles não concordam e apresentam argumentos destinados a persuadirem-se mutuamente a fim de poder tomar uma decisão comum. Essa troca verbal não visa estabelecer uma verdade absoluta que não existe nas atividades humanas, mas encontrar um acordo sobre o razoável, sobre o que parece verossímil e plausível ao homem racional em determinadas circunstâncias. É a natureza do debate democrático, no qual as decisões são tomadas majoritariamente na sequência de uma troca de pontos de vista conflituosos.

Nessa perspectiva, pode-se considerar que o que se chama de polêmica é uma troca inflamada na qual se confrontam opiniões violentamente opostas que não convêm à deliberação democrática. De acordo com o objeto das Ciências da 
linguagem e argumentação retórica, há a possibilidade de estudar um debate em torno de uma questão de interesse público. Primeiramente, é necessário que a polêmica seja sobre um assunto de interesse público para que ela não seja uma simples querela, uma disputa entre particulares. A polêmica pode, evidentemente, se desenvolver sobre a base de uma questão privada no início, um conflito de aluguel, por exemplo, mas é necessário que esse conflito se torne público questionando grandes princípios e grupos de defensores que se apegam a eles. Segundo ponto, um debate ancorado na atualidade destaca a que ponto a polêmica que trata de questões de interesse público está apoiada na atualidade. Quanto tempo esse episódio ficará ou ficou nas mentes? Estreitamente ligada àquilo que preocupa o público num momento preciso, a polêmica é efêmera e frequentemente tão rapidamente esquecida quanto cheia de razão quando ela eclode. Por isso seu sentido e seus anseios cessam de ser perceptíveis para além da duração de sua vida, por outro lado, do espaço cultural no qual ela emergiu. Para o analista do discurso, assim como para o sociólogo e o historiador, a polêmica se mostra, ao contrário, rica de ensinamentos na medida em que ela revela muitas coisas sobre a sociedade e a época na qual o discurso polêmico circula na praça pública. A polêmica é, portanto, um debate em torno de uma questão da atualidade, de interesse público, que comporta os anseios de sociedade mais ou menos importantes numa dada cultura. Um modo de gestão do conflitual é a dicotomização, a polarização ou a divisão social. Nesse sentido, pode ocorrer a desqualificação do outro na relação entre os atores.

Na segunda parte do desenvolvimento da obra, as reflexões envolvem o papel do discurso e a interação polêmica. Esse capítulo explora as modalidades discursivas e argumentativas da polêmica em exercício, isto é, seleciona exemplos concretos para explicar seu funcionamento in loco. Analisar como se dá a distinção entre o discurso polêmico e a interação polêmica, como no Caso da Burca e a exclusão das mulheres no espaço público em Israel. É o exame das práticas polêmicas que conduz a respostas.
O analista, na medida do possível, deve examinar os discursos abordados sem julgamentos, pois não pode se tornar polemista, deve manter, contudo, a neutralidade engajada para observar os debates polêmicos: seu surgimento, sua regulação, seus papéis sociais e, por meio dele, compreender melhor o funcionamento das democracias pluralistas contemporâneas nas quais vivemos.

Na terceira parte, razão, paixão e violência: o debate sobre os bônus e a opção de compra de ações em tempo de crise; a violência verbal: funções e limites e as discussões inflamadas nas conversas digitais compõem a análise da polêmica desses discursos que revelam a complexidade dos debates públicos observados in loco concretamente. É possível, então, mergulhar na materialidade da linguagem, através da circulação dos argumentos em determinado contexto e perceber as múltiplas polêmicas que invadem o universo social e esclarecer a lógica que subjaz na racionalidade da paixão, ou quais são as razões das emoções.

Como se fosse uma breve conclusão, é importante ressaltar a relevância do estudo de Amossy ao trazer, à superfície das relações do espaço público, a apologia da polêmica como uma modalidade de interação que é o reflexo de escolhas de sujeitos em processo de desenvolvimento e aprendizado dos recursos e estratégias da linguagem comunicativa que organiza o pensamento para atuação e domínio dos campos da vida pública. Numa sociedade dividida em que o conflito de opiniões permanece como regra, se o desejo for a preservação do pluralismo e sua diversidade, a polêmica pública proporciona um meio de protestar contra o intolerável, reagrupar identitários, gerenciar desacordos sem degenerar em manifestações sociais e violências entre cidadãos e justificar a "coexistência no dissenso". Ler a obra de Amossy é instrumentalizar-se para o agir comunicativo em que razão e sensibilidade participem em equilíbrio na determinação da conduta cidadã em todas as searas da vida humana. 
